\title{
Heterogeneous Method for the Oxidation of Alcohols under Mild Conditions with Zinc Dichromate Adsorbed on Alumina
}

\author{
N. Feizi, ${ }^{*}$ H. Hassani, and M. Hakimi ${ }^{\dagger}$ \\ Department of Chemistry, Payam Noor University, Mashhad,_Iran. *E-mail:feizi_n@pnu.ac.ir \\ †Department of Chemistry Payam Noor University, Fariman, Iran \\ Received June 16, 2005
}

Key Words : Zinc dichromate, Alumina, Oxidation, Alcohol, Carbonyl compound

Chromate salts and other chromium (VI) oxides have been widely used as oxidizing agents for a variety of substrates ${ }^{1}$ including alcohols. ${ }^{2}$ These oxidants are frequently used in large excess but can also be used catalytically in conjunction with secondary oxidants. ${ }^{4}$ Problems in the use of chromium (VI) complexes as oxidation reagents include the lack of selectivity in oxidations, safety hazards associated with the use of large quantities of toxic compounds, cumbersome preparation and potential danger (ignition) in handling its complexes, difficulties in terms of product isolation and waste disposal and the need for aqueous acidic or basic conditions for reactions of chromate salts.

These problems could be eliminated by reagents on solid supports. Many oxidants, especially the older and stronger chromium oxidizing agents, may have their reactivity and selectivity modified by adsorption onto inert supports. ${ }^{5}$ There were many chromium oxidants on inert inorganic supports such as: pyridinium chlorochromate on alumina, ${ }^{6}$ pyridinium chromate on silica, ${ }^{7}$ chromic acid on alumina ${ }^{8}$ and silica, ${ }^{9}$ chromyl chloride on silica - alumina ${ }^{10}$ and resin, ${ }^{11}$ poly(vinyl pyridinium chlorochromate (PVPCC) ${ }^{12}$ and poly(vinyl pyridinium dichromate, ${ }^{13}$ chromium VI oxide $^{14}$ prepared and used for the oxidation of organic compounds.

In this paper, we wish to report the utilization of zinc dichromate $^{15}$ onto alumina as a convenient, efficient and economical reagent for the oxidation of alcohol to carbonyl compounds in $\mathrm{CH}_{3} \mathrm{CN}, \mathrm{H}_{2} \mathrm{O}$ and solvent-Free conditions. (Table 1, Scheme 1)

The rate of oxidation and yield of product depended on the nature of the substrate and reaction condition. Oxidation of benzylic alcohols proceeded more rapidly than the oxidation of aliphatic alcohols (Table 1). In the oxidation of benzyl alcohols to benzaldehyde, when there is an electron releasing group, the rate and yield of the reaction increased (Entry 1-3). 4-Nitro benzyl alcohol is oxidized to its corresponding aldehyde within a longer time and 80-85\%

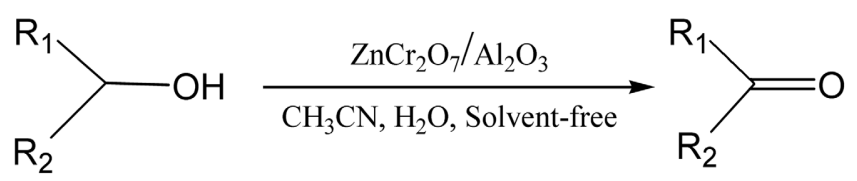

Scheme 1 yield. Primary and secondary aliphatic alcohols (Entry 1012) are oxidized to the corresponding carbonyl compounds under these conditions. Reaction in solvent-Free conditions is of a high yield and faster than reactions in water and acetonitrile. The reactions are relatively clean with no tar formation and no over oxidation to carboxylic acids. The reaction of cinnamyl alcohol gave cinnamaldehyde with a high yield without cleavage of benzylic double bond. (Entry 9)

The acidity of zinc dichromate/Alumina ( $\mathrm{pH}$ of 0.01 molar solution: 4.65) is less pronounced than those reported for pyridinium chlorochromate $(\mathrm{pH}$ of a 0.01 molar solution: 1.75 ) and pyridinium fluorochromate ${ }^{16}(\mathrm{pH}$ of a 0.01 molar solution: 2.45$)$.

This reaction has several interesting features: 1) Yields are satisfactory. 2) The reaction is specific, avoiding over oxidation of aromatic aldehyde into acid. 3) The reagent is cheap and easy to prepare. 4) The reaction is performed under mild conditions, in $\mathrm{CH}_{3} \mathrm{CN}, \mathrm{H}_{2} \mathrm{O}$ and solvent-free at room temperature. 5) The experimental set-up and work-up are exceedingly simple.

\section{Experimental Section}

Preparation of alumina supported zinc dichromate. To the cold solution of chromic acid (23.6 g), prepared by the addition of chromium trioxide $(20 \mathrm{~g})$ to a 3.4 molar solution of sulfuric acid $(59 \mathrm{~mL})$, zinc carbonate $(12.5 \mathrm{~g})$ is added in portions within $15 \mathrm{~min}$. A dark reddish solution is produced. Neutral alumina (65 g, Aldrich. BrockmannI- 150 mesh) is added to a solution. 30 min evaporation of the solvent under vacuum affords orange-red slurry, which is completely dried on the surface of highly dried day plate in the air. Yield $90 \mathrm{~g}(80 \%)$.

Oxidation of alcohols by $\mathrm{ZnCr}_{2} \mathrm{O}_{7} / \mathrm{Al}_{2} \mathrm{O}_{3}$ in $\mathrm{CH}_{3} \mathrm{CN}$ or $\mathrm{H}_{2} \mathbf{O}$. To a solution of alcohol $(1 \mathrm{mmol})$ in $\mathrm{CH}_{3} \mathrm{CN}(5 \mathrm{~mL})$ or $\mathrm{H}_{2} \mathrm{O}(5 \mathrm{~mL})$ was added $\mathrm{ZnCr}_{2} \mathrm{O}_{7} / \mathrm{Al}_{2} \mathrm{O}_{3}$ (2-3 g). The resulting mixture was stirred at room temperature. The progress of the reaction was monitored by TLC. After the completion of the reaction, silica gel $(1 \mathrm{~g})$ was added to the mixture and the solvent was evaporated under reduced pressure. The resulting material was added on silica gel pad ( $3 \mathrm{~cm}$ thick). The filter cake was washed with $n$-HexaneEthyl acetate $(4: 1)$ and the solvent was evaporated to afford 
Table 1. oxidation of alcohols with $\mathrm{ZnCr}_{2} \mathrm{O}_{7} / \mathrm{Al}_{2} \mathrm{O}_{3}$

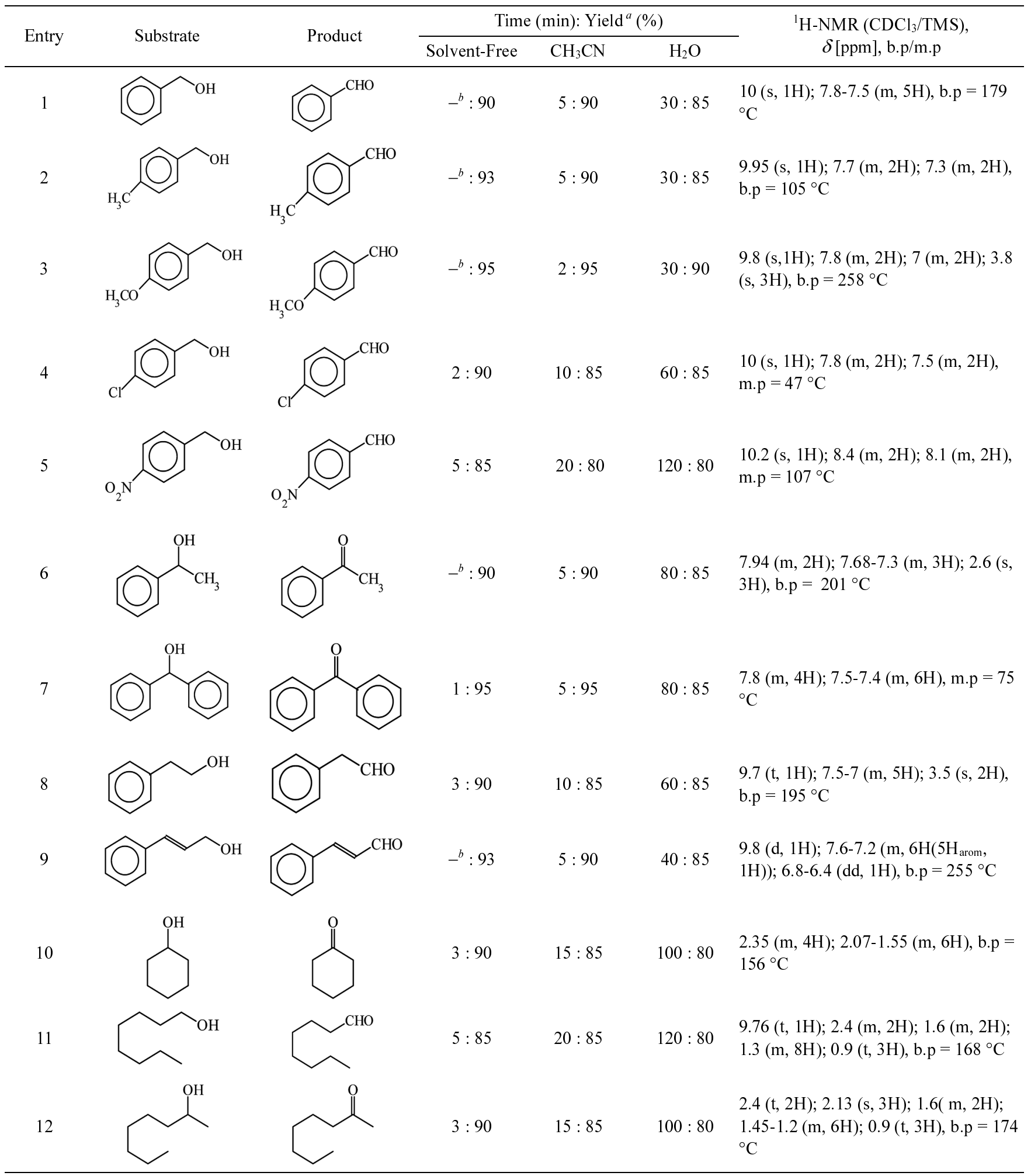

${ }^{a}$ Yields refer to isolated products and 2,4-dinitrophenyl-hydrazine derivative. Structures are confirmed by ${ }^{1} \mathrm{H}-\mathrm{NMR}$, mp/bp. ${ }^{b}$ The reaction was performed immediately.

the desired product in excellent yield.

Oxidation of alcohols under solvent-Free condition: A mixture of alcohols $(1 \mathrm{mmol})$ and $\mathrm{ZnCr}_{2} \mathrm{O}_{7} / \mathrm{Al}_{2} \mathrm{O}_{3}(3 \mathrm{~g})$ was ground at room temperature. The progress of the reaction was monitored by TLC. After the completion of the reaction ether $(30 \mathrm{~mL})$ was added and filtered through a silica gel. The combined filtrates were evaporated. The filter cake was purified by a short pad washed with $n$-Hexane-Ethyl acetate $(4: 1)(50 \mathrm{~mL})$ and the solvent was evaporated to afford carbonyl compound in high yield. 
Acknowledgements. The authors wish to thank the Payam Noor University for the support of this work.

\section{References}

1. For reviews, see: (a) Cainelli, G.; Cardillo, G. Chromium Oxidations in Organic Chemistry; Springer-Verlag: Berlin, 1984. (b) Wiberg, K. B. Oxidation in Organic Chemistry; Academic press: 1965. (C) Muzart, J. J. Bull. Soc. Chim. Fr. 1988, 65. (d) Sheldon, R. A.; Kochi, J. K. Metal Catalyzed Oxidations of Organic Compounds; Academic press: New York, 1981; chapter

2. (a) Piancatelli, G.; Scettri, A.; D'Auria, M. Synthesis 1982, 245. (b) Collins, J. C.; Hess, W.; Frank, F. J. Tetrahedron Lett. 1968, 3363.

3. Sharpless, K. B.; Akashi, K. J. Am. Chem. Soc. 1975, 97, 5927.

4. (a) Corey, E. J.; Barette, E. P.; Magriotis, P. A. Tetrahedron Lett. 1985, 26, 5855. (b) Muzart, J. Tetrahedron Lett. 1986, 27, 3139.

(c) Kanemoto, S.; Oshima, K.; Matsubara, S.; Takai, K.; Nozaki, H. Tetrahedron Lett. 1983, 24, 2185.
5. Mckillop, A.; Young, D. W. Synthesis 1979, 401 and 481.

6. Cheng, Y.-S.; Liu, W. L.; Chen, S.-H. Synthesis 1980, 223

7. Singh, R. P.; Subbarao, H. N.; Pev, S. Tetrahedron 1979, 35, 1789.

8. Santaniello, E.; Ponti, F.; Manzocchi, A. Synthesis 1978, 534

9. (a) Lou, J. D.; Wu, Y. Y. Chem. Ind. (London) 1987, 531. (b) Lou, J. D.; Wu, Y. Y. Synth. Commun. 1987, 17, 1717.

10. San Filippo, J.; Chern, J. R. J. Org. Chem. 1977, 42, 2182.

11. Cainelli, G.; Cardillo, G.; Orena, M.; Sandri, S. J. Am. Chem. Soc. 1976, 98, 6737.

12. Frechet, J. M.; Warnock, J.; Farall, M. J. J. Org. Chem. 1978, 43, 2618.

13. Frechet, J. M.; Darling, P.; Farall, M. J. J. Org. Chem. 1981, 46, 1728.

14. Lalancetle, J. M.; Rollin, G.; Dumas, P. Can. J. Chem. 1972, 50, 3058.

15. (a) Schulze, J. Z. Inorg. Chem. 1895, 10, 148. (b) Firouzabadi, H.; Sardarian, A. R.; Moosavipour, H.; AFshari, G. M. Synthesis 1986, 285.

16. Bhatlacharjee, M. N.; Chaudhuri, M. K.; Dasgupta, H. S.; Roy, N. Synthesis 1984, 588. 